\title{
Civilisations
}

Revue internationale d'anthropologie et de sciences

humaines

44 | 1997

Les peuples des forêts tropicales

\section{Reactions to cultural change}

Among the Eipo in the Highlands of West-New Guinea

Wulf Schieffenhövel

\section{(2) OpenEdition}

\section{Journals}

\section{Electronic version}

URL: http://journals.openedition.org/civilisations/1632

DOI: $10.4000 /$ civilisations. 1632

ISSN: 2032-0442

\section{Publisher}

Institut de sociologie de l'Université Libre de Bruxelles

\section{Printed version}

Date of publication: 1 January 1997

Number of pages: $220-227$

ISBN: 2-87263-122-4

ISSN: 0009-8140

\section{Electronic reference}

Wulf Schieffenhövel, « Reactions to cultural change », Civilisations [Online], 44 | 1997, Online since 29 June 2009, connection on 01 May 2019. URL : http://journals.openedition.org/civilisations/1632 ;

DOI : 10.4000/civilisations. 1632 
REACTIONS TO CULTURAL CHANGE Among the Eipo in the Highlands of West-New Guined

WUIf SCHIEFENHÖVEL 


\section{INTROOUCTION}

The Eipo of Irian Jaya, the Indonesian half of New Guinea, were first contacted by Pierre Gaisseau and his expedition who crossed this part of the big island from south to north in 1959. Material acculturation started, on a small scale, about a decade later. Changes of mental, religious and social concepts began, on a big scale, with the missionizing efforts of a fundamentalist Christian group (Unevangelized Fields Mission, UFM). A number of ecological changes were initiated by our interdisciplinary team of scientists, e.g. the introduction of chickens and some metal tools. The growing influence of the mission, heginning after the severe earthquakes in 1976, changed almost all spheres of life, from the physical structure of the villages to cosmogonic concepts and sacred rituals. There is no or at least no major influx yet of mining companies, the Indonesian government or military nor of islamic settlers, all of which are present already in various areas of the country. But there can be no doubt that massive changes are to come.

In many ways this imminent shift to cosmopolitan culture (Coca Cola and the like) and to the specific Indonesian version of it will further challenge the cultural fundaments of these people who had survived in the isolated mountains of central New Guinea since the first arrival of their Papuan ancestors approximately 50.000 years ago. They had survived not only physically but with the whole mental and social infrastructure typical for Homo sapiens everywhere : the intricate set of norms, rules and traditions which are the result of interplay between our biological endowment and the forming forces of culture.
The Eipo, as their neighbours in the rugged interior of New Guinea had, in the last millennia, lived in relative harmony with nature. Not, as I am convinced, primarily because they chose to do so out of insight but rather because they did not have the technological means to change nature in the way members of industrialized cultures are doing this. Humans are, by their very nature, geared to shortterm and midterm gains, trying to maximize benefits for the moment or the forseeable future. Their foresight is restricted to a limited timespan, perhaps the future lives of their grandchildren. The eradication of the big flightless Moa bird in New Zealand by early Maori is one of the examples for this

on the other hand, of course, one finds many elements in traditional cultures which stabilize various equilibria. Among the Eipo we documented [Schiefenhövel, 1989] an astounding autoregulation with regard to population size. It was the right of the mothers to not except certain of their newborn children. This descision was much more often made in cases where the baby was a girl. This led to a shortage of girls, young and middle aged women and thereby reduced possible population growth. In the Southern Eipomek valley on average one woman had one daughter who survived to complete her reproductive cycle : the epitomy of balance in population dynamics. The influence of the mission started to change this pattern and it is to be expected that along with a modest improvement of health conditions (especially due to modern antibiotics) the Eipo as other populations in New Guinea and Melanesia will have to face major problems of overpopulation. Already this region is growing, in 
numbers of people, faster than any other area of the world today.

\section{A HWIFE IS MORE THAN A TOOL}

Bongto, one of our friends in the remote Eipomek valley in the high mountains of WestNew Guinea, had stuck a kitchen kuife into the thigh of her husband Tinteningde. Marital tension, as in other societies, sometimes turns to violence among the Eipo. The knife had been a present from us. And this was the reason why a messenger was sent from Iingerkon to the white doctor. When I, equipped with my medical kit and after an alpine climb, arrived at Dingerkon, so spectacularly sitting at the edge of a vertical cliff, I examined the injury and found it much less serious than the excitement had let me to believe. I asked why they were so concerned. They said : «You see, the wound was made by this new type of knife. If it had been caused by one of our tools, we wouldn't have worried so much. But we don't know the kuemelina (primordial origin, sacred, mythical essence) of this thing. It belongs to your kuemdina. That is why we sent a boy to fetch you».

Material things, which we, in our disposalculture, handle with a certain anonymity and neglect, are, for New Guineans, not just solely objects. They have a history and a meaning which one, not unlike a modern historian, takes into account. In this chapter, I will attempt to shed some light on one side of the Papuan character : its outspoken pragmatism. It became vividly apparent in the first time of our encounter with the Eipo, who, at the time of our arrival, had a complete neolithic inventory of tools and, much more important, unshaken trust in their own way of life.

\section{THE EPO - HISTORY OF CONTRCT}

In June 1974, after six days of crossing mountain ranges, rivers, rainforests and anthropogenic grassland, we arrived in that part of the Eipo country which later became the center of our interdisciplinary research programme, initiated by Gerd Koch and Klaus Helfrich of the Museum für völkerkunde in Berlin and funded by the Deutsche Forschungsgemeinschaft [Schiefenhövel, 1976; Koch, 1977]. This part of the valley, named $\mathrm{X}$-valley by the mission pilots because of the shape of a junction of rivers further down, had been visited by Pierre Gaisseau's expedition during their heroic walk from the southern to the northern coast of then Dutch New Guinea in 1959 [Gaisseau, 1959; Saulnier, 1963], a group of Indonesian military personnel, again led by Pierre Gaisseau, parachuting into the valley ten years later [Lanoran, 1969] and a few missionaries of the Unevangelized Fields Mission on their way through one of the last pagan areas to stake out their claim. The first expedition and the missionaries just stayed a night or two, the members of the military team spent three weeks in the area; they were the first to bring back some data to the outside world, among others a rough, short vocabulary.

The Frenchmen of the 1959 Trans-New-Guinea expedition and those of their carriers who survived the ordeal of crossing the central cordillera at an altitude of $3.700 \mathrm{~m}$ were the first strangers the Eipo ever saw. On the high pass I could still photograph the femur bone of one of 
the lowland carriers who must have been frightened and frozen to death in this unknown alpine terrain, the abode of creator gods and the souls of the dead. The Eipo experienced, as they told us, the strange men, their tents, iron axes and other equipment with awe. They believed them to be supernatural beings, whose threatening aspects were slightly diminished because of their poor physical performance and the apparent strain with which they moved through the rugged country, in which the indigenous people travel so effortlessly. Only the toughest and most determined of the crew reached Hollandia on the northern coast. The others, sick and worn out, were picked up by a seaplane at the Idenburgh River, north of the mountain range. They left little trace on their trail. The lijpo were afraid to accept steel axes from them even though the superiority of this tool over their stone adzes was demonstrated to them. Not to become involved was their line of action, as they told us 15 years later. Small pieces of green canvas were the only visible remains of the ghostly appearance of the first foreigners.

The men of the second expedition fell out of airplanes, dangled under parachutes and dropped, scattered out, into partly inaccessible terrain, making it difficult for the group to unite again. Signalling flares were used to find each other. E.po boys, adolescents and men were secluded in a bush house at that very time to carry out an initiation ceremony (kwit). They were, as everybody else in the valley, scared by the strange events, and this is why those who were initiated at that time were later called bondan ukue diniblenang, «those who were afraid of Bondan's fire». Dr. Bondan was the military doctor of the team and had apparently impressed the locals more than the other soldiers or the Europeans of the group. Despite their scary fall from the sky the team had quite friendly interactions with the population of the Eipomek and Fa valley and, in the further course of their march, the people east of there. The majority of the Eipo classified the strangers as ordinary humans even though not everybody was too certain about this taxonomy. The amount of verbal exchange was of course rather limited, especially as the visitors lived in a camp outside of Munggona. From there they walked east and eventually launched rubber rafts in an attempt to reach the Idenburgh river. It was only due to their still functioning 2-way radio and a helicopter rescue operation that they survived the aquenus adventure. The rafts had capsized, some members suffered injuries and much of the material, including a movie film, was lost.

Our own arrival, $41 / 2$ years later, in the same rather humiliating way of locomotion as the 1959 expedition, stumbling exhaustedly over mountains, slippery ground and mostly invisible paths, met considerable skepticism by the villagers of Talim who had been outside of most of the acculturation-events so far. The men, carrying bows and arrows as every adult male at almost any time, formed a living wall across the entrance to their hamlet. We had arrived the day before, our aluminium boxes, shining in the afternoon surn, our many helpers from further east carrying them down from the last pass. The camp we put up just hefore night fell was close to the village, too close to be an acceptable distance. Understanding their signs we started walking again until we reached a relatively open area with secondary grassland not 
far from the village of Munggona. Some men had already gathered. The news of our venture had of course always travelled ahead of our desperately slow lindworm. One of the men, a muscular, vital pygmy (Eipo male average body height is $146 \mathrm{~cm}$ ) took me by his hand. Later I learned his name : Irim. We ran to one of the hills from where we could see much of the area. He kept pointing into different directions, pouring fast unintelligible words over me. Yet, I understood : He was explaining his home country. We were accepted. We pitched our tents 10-15 minutes walk from the nearest village and I begun to treat patients who immediately flocked in our camp. The news that a white healer was among the strangers, who had cured sick people further east, had also arrived before us. The Eipo, exclusively men at first (males are responsible for possibly dangerous outside contact; women are protected from external contamination), swallowed tablets and tolerated intramuscular injections without any problem. Each of them also seemed to answer my question : «An si?», what's your name? It was only later when I had mastered the first steps into this highly structured language, that I realized what these names meant : Na-si-gumnye, Na-si-walwal, Na-siurang, "I-the-one-who-has-no-name", «Myname-I-don't-know', "I-am-somebody-else». To give away one's clibe si, the "real name», exposes oneself to possible harm. To entrust the symbol of one's personality into unknown minds... it was too early for that. Later, when we knew the villagers and their relatives in other valleys and had noted down as much of their genealogy as we could, we laughed together about this hidden sign of mistrust and fear.
Two of our team became sick and had to leave for Germany. The remaining three, Gerd Koch, our «elder», my wife Grete and I soon were able to move into houses huilt for us in two different villages. The routine of anthropological fieldwork hegan.

\section{THE STONE AGE BOMB ANO OTHER PPOOFS OF PRAGGMTISM}

Our hosts were at least as curious as their professional manwatchers. When we, still in our makeshift camp, played back to them their own voices via tape-recorder, in order to verify informations we had got, they were however $\mathrm{s} \cap$ frigh $1-$ tened that we stopped doing that for a month or so. But they got quickly used to us and were very keen, very intellectual observers of all the new things we had. Gerd Koch one day dismounted his kerosene pressure-lamp, a slightly stripped down Chinese replica of the famous German «Petromax" lantern. One of his Eipo friends, who had most certainly never seen such ingenious invention, was watching him intensely. Having cleaned the small pipe and the tiny jet hole which always gets blocked, thereby stopping the scientist's brilliant nocturnal insights to be written down for eternity, he started to reassemble the elements, got, however stuck at a certain stage. The Eipo mechanic calmly pointed to one of the small pieces and to where it belonged. The lanterns successful repair was ensured.

Some other observations may be mentioned to illustrate the intelligence and the pragmatism of our stone age hosts. Right from the beginning I had started to build an airstrip. The interdisciplinary programme involving more than 
30 scientists could not possibly be carried out without such shortcut to the outer world. The Eipo were, quite in contrast to our expectations, keen to help us. For very similar reasons the inhabitants of the Rai Coast were enticing Peter Lawrence [1964] to assist them in establishing a landing site for the big noisy birds carrying cargo in their bellies. From their neighbours in the east, west and south, where groups of fundamentalist churches had already built airstrips and stations by 1974 , the Eipo knew that the onset of modern times, i.d. the influx of new, badly wanted goods, was connected to white people and their way of bringing cargo through the air. Our hosts' willingness to help us do the heavy work of digging the drenches at the sides, cleaning up to $1 \mathrm{~m}$ of swamp by the Herculean method of utilizing a nearby stream, cracking huge rocks by fire and creating a moderately even gravel surface with nothing but 15 spades, can best be explained as being motivated by the desire to participate in the potential flow of cargo.

A few weeks after we had started our nonsophisticated construction work and had laid out the general size and shape of the future airstrip I had to walk to Bime, the mission station with a landing strip from where we had begun our expedition. A surprising number of men volunteered to come along. As soon as we had arrived in Bime my companions tied some long pieces of liana together and, without delay, set out to span this "rope» across the width of the strip. "Ke fol kiklibnab", we will compare the plane's wings (precisely : the axillary wings, as opposed to the tail wings, amwe fol) they answered my puzzled looks. Back in the Eipomek valley they unrolled the fibrous measuring device and stretched it out between the water ditches of our strip. The distance was the same. . . as ruled by the Department of Civil Aviation. My construction workers' minds were put at rest. They had not trusted my knowledge as airstrip engineer and wanted to be sure that all effort to be put into what in their view was an enormous field would not be in vain.

I was fascinated by this proof of neolithic ingenuity. The Eipo had, at an instance, found a way to gage the universal airstrip width - something like the platinum meter stick of Paris. Yet, levy-Bruhl's «L'homme prélogique» was going to be disproved many more times.

Most strikingly perhaps on the anxiously awaited day of the first landing on our strip, which had taken almost exactly one year to be completed. Glen Laird, the chief pilot of AMA, the protestant missions' airline, touched down, praised us for the hard surface, and asked me to join him for the second take off. Everything went well. He now wanted to put on some more weight to find out the maximum take off load for our rather short strip and suggested to ask some local people on board. Here was my chance to do something official, ceremonial, in order to express my gratitude to the Eipo for helping to build the landing strip. I invited a few of the sisinang, the leading men of the valley, to place their naked behinds on the Cessnas plastic seats. They accepted, exhibiting no signs of fear. But before pushing their penis gourds up to squeeze themselves through the narrow entrance they had a few requests : «Tell the pilot to leave the door-closing-board behind as he had done it when you were getting airdrops!» «You will be 
very cold, my friends, high in the sky with the cold air blowing all over you!» «Don't worry, we are used to get very cold in the big mountains. Tell the pilot to leave the door open and that we are going to take some heavy rocks with us.» «Holy pig's fat, what do you want to do with them?», «Well, when we fly over the village of our enemies, we'll just drop them".

The bomb was invented. I shuddered. Wasn't it enough to marvel at the miracle of heing able to fly like the birds, to see one's home country from above, to cover distance like lightning? No. The plane was going to be used as the ultimate weapon against the age old, now defenseless enemy in the next valley. It took a bit of persuasion to make the 20th century warriors give up their splendid plan.

Eipo pragmatism sometimes took on forms which our ethnocentric minds did not forsee. Empty tins, for instance, were, especially in the beginning, not cherished for being handy watertight containers but because of their shiny appearance and striking effect in all kinds of fashionable body decorations. Plastic parts from broken typewriters, pieces of tom aluminium and small nuts, bolts and everything new was foremost judged upon its power to enhance one's beauty, used as necklace, armband, headdecoration and the like. Many a ballpoint pen was thus, after completing its life as writing tool, recycled as striking nose stick. A visitor from a distant mission station sported an empty Coca Cola can as dernier crie ear plug.

As time went by, more and more Western items were included in the Eipo inventory of tools. Razor blades, always broken in halves to serve two owners, were used, even by children, free-handedly, to shave off the fuzzy hair of their friends, uncles or parents. Never was there any blood shed or even a cut to be seen on the scalp, barely wettened by a few drops of water pressed out from a banana trunk. Steel axe and bush knife were highly valued, as were kitchen knives and empty rice bags. Our Eipo friends quickly understood the advantages of writing notes and communicating by two-way radio and learned, by the way, in the very short period of two years, to read and write, despite the rather insufficient school education they received. Before that, they were using our walkie-talkies to converse with their friends in villages where one of our team was participating in the daily round-calls. They understood immediattely, from watching us, the unidirectional mode of transmission and never finished their bits of small talk by firmly stating «0vang and out!»

Of course, they had theories about how it was possible to send the voice beyond the normal hearing distance. For the powerfull single-side-band transceiver connecting us with the provincial capital Jayapura, mission stations and, most importantly, the pilots, the idea was like this : The long bipolar antenna stretched out between two large poles in front of my house was thought to be an equivalent of lianas hanging down from the sky, visible only to seers, asing ketenenang (those whose eyes are sharpened). These lianas serve the souls of all animals for their nocturnal climb into the sky, where they gather to dance around flickering fires - the stars we humans can see from below. Similar lianas can carry the searching souls of seers to find out about distant events. The spoken words to the microphone of our transcei- 
ver were, quite obviously, strung first along the visible antenna wire and then fed into the system of liana strings to reach far away places.

Their efforts to integrate the unheard into their epistemology and cosmological system did not suppress, however, their realistic approach and general pragmatism. Being responsible for the outside contact of our team I was sitting in front of our single-side-band transceiver one morning, patiently repeating the prescribed formula : «Jayapura, Jayapura, - Eipomek.....». One of the Eipo friends was standing at the door, manwatching me and my futile efforts to elicit some response from the silent box. Seeing my face getting more and more frustrated and angry he said calmly : "COInitiate, there's no voice in your box, eh? Last time I saw you talking to it your had the fibre stuck into its back. Now it's dangling loose. How about you try sticking it back in?». Because of a thunderstorm the night before I had disconnected the antenna fearing that our only contact to civilization might be blown off. "lipomek, Eipomek Jayapura", the box echoed the educated voice of the American lady in the main mission office. The stone age villager had put us back into the air.

\section{CONCLUSION}

It would be worthwhile to also dwell a bit on the traditional wisdom of these mountain Papua, their intimate knowledge of plants, animals, of body and nature of humans, their way to classify and explain the world. And to show that in a number of cases they were better natural scientists than our highly learned botany and zoology specialists. But we have attempted to do that at other occasions [e.g.Hiepko \& Schiefenhövel,
1987). Therefore, I can refrain from going into this topic here, except stating that woman-man, wherever they live, are born scientists and intellectuals. They know infinitely more than is necessary for mere survival. One can only hope that this ability will enable them to cope with the rapid process of acculturation. 